\title{
BASIC PARAMETERS AND CHARACTERISTICS OF SEISMICITY IN MONGOLIA
}

\author{
Klyuchevskii A. V., Bayart G., Demjanovich V.M. and Dugarmaa T.
}

\section{Introduction}

Much of the territory of Mongolia is located in highly seismic areas of CentralAsian seismic belt and is subjected to frequent and large earthquakes. Its western half is particularly seismically dangerous. Only in twentieth century more than 60 earthquakes with $M>5.5$ (7 to 11-12 - intensity) occurred here, among which tens of earthquakes were responsible for severe destruction of the earth surface, and seismic disasters of 1905, 1931 and 1957 were accompanied by seismotectonic deformations to several hundred kilometers in length. Judging from the retained traces of ancient earthquakes and the chronicles, similar and probably larger seismic events occurred here in the recent past [1]. Individual regions of Mongolia experience fast deformations occurring as a response to collision of Indostan and the rest part of Eurasian continent [2]. Strike-slip faulting plays a dominant role in active tectonics of Mongolia, but in the Khubsugul region the character and the style of ruptures becomes more complicated [3-6], and in the Baikal rift zone under conditions of near-horizontal extension normal faulting is predominant [7], which is caused by raise of mantle diapir and spreading of upper mantle [8-13] and partly by influence of collision [14].

Under conditions of conservative geological medium and consistency of action of sources of recent geodynamic transformations it can be roughly assumed that during small time spans brittle destruction of the earth crust will occur at the same places and at constant time intervals. This results from invariability of boundary and initial conditions such that zero value of the coefficient of intensity of stresses of shear fracture is retained [15]. However, current investigations showed that stress - and strain state of the earth crust in the Baikal rift zone, like other continental rifts [16], may undergo sharp variations over fairly small time spans [17-19]. Instrumental data for almost 30 years revealed two lengthy episodes of exchange by axes of maximal and intermediate stresses in the stress field of the Baikal region [20].

Thus, condition of constancy of action of global sources of geodynamic conversion is not fulfilled even within the small time spans. If variations and superpositions of stress fields of regional and local nature caused by redistribution of stresses and deformations after large earthquakes are taken into account, the stress - and strain state and seismicity of tectonically active areas of the earth crust of Mongolia-Siberian region are in the conditions of constant spatio-temporal transformations. These cyclic processes characterized in mesomechanics as fatigue ones [21,22], result in inhomogeneity and nonstationarity of seismic field. Therefore, 
without rejection of the first approach one should come to the second, third and other approaches in investigating seismicity of the territory.

The actual materials used and the methods of their processing and analysis play an important role in this process of knowledge of the nature of seismic phenomena.

\section{Analysis of instrumental seismological data}

Monitoring of seismicity is an important and sensitive instrument in studying seismotectonic and geodynamic processes, in seismic zoning and earthquake prediction. Thus, in terms of the model of seismic quiescence, increase of mean earthquake occurrence rate in a large area around the large shock in future [23, 24] takes place with decreasing occurrence rate within a source zone of an earthquake [25-27]. Firm data on seismicity and seismic regime as a function of space, time and energy are required first to distinguish these phenomena.

Seismological data obtained by the seismograph network of the Baikal region and Mongolia over the period of instrumental observations of 1964-1999 are used in this study. It is known that development of seismograph network on the territory of Mongolia followed the path of progressive increase of the number of recording stations $[4,28,29]$. Typical equipment is used in the seismograph network of the Baikal region and Mongolia, and standard methods of seismic data recording and processing correspond to the instructions [30,31]. One of the basic products provided by regional network of seismic stations is an earthquake catalog, which contains for each shock time of its origination, geographical epicenter coordinates, class of precision of their determination and energy class Kp on T. G. Rautian's scale [32]. Earthquake epicenters are determined mainly from observations of direct shear waves. For most earthquakes the uncertainty of epicenter coordinate determination is no more than $5-10 \mathrm{~km}$. It is to be noted that data exchange between regional Altai-Sayan, Baikal and Mongolian networks of seismic stations is a standard practice in a cumulative processing of the material. Therefore, we combined the catalog data of the Baikal region and Mongolia as a result of which the most complete representative samplings of seismological materials were provided for the northern part of Central Mongolia, which includes the entire Khubsugul and partly KhankhuheiBolnai and Orkhon-Tola regions. These regions may be considered as having data of representative recording of earthquakes from energy class $\mathrm{Kp}=8[33,34]$.

In evaluating representative energy class of earthquakes in Mongolia and individual regions the values of mean energy class of shocks Kay, calculated for these territories from the materials of joint earthquake catalog, were correlated with the model values of mean energy class of earthquakes $\mathrm{Km}$, estimated for the corresponding value of ${ }^{\wedge}$ parameter - slope of the recurrence plot (Table). The table gives the results of calculations and determinations of basic parameters of seismicity and associated geologic and geophysical characteristics of the territory of Mongolia, separate areas and regions which analysis makes it possible to draw 
the following conclusions about the representative completeness of initial data samplings used: First, earthquake samplings of northern Mongolia which includes the Khubsugul, Khankhuhei-Bolnai and Orkhon-Tola regions are representative with $\mathrm{Kp}=8(\mathrm{MLH}=2.5)$. Second: earthquake samplings of southern and western Mongolia, Gobi-Altai and Mongolia-Altai regions approach the representative class Kp=9 (MLH $=3.0$ ). Throughout the territory of Mongolia the representative class of earthquakes is equal to $\mathrm{Kp}=9(\mathrm{MLH}=3.0)$.

\section{Epicentral fields and a scheme of regionalization of the territory}

Since peculiarities of internal geologic and geophysic structure of the region and state of stress and strain of its interior parts are reflected in the epicentral field of earthquakes, in a complex of seismicity investigation prominence is given to the study of regularities of epicentral field. Investigations of spatio-temporal and energy regularities of earthquake distribution in Mongolia is performed on the basis of the map of epicenters of 1994 earthquakes with $K p>=8$ and the map of epicenter density of 38002 shocks with $\mathrm{Kp}>=7$ (Fig. 1), recorded for the instrumental period of observations from 1964 to 1999. The degree of correspondence of epicenters of ancient and recent earthquakes can be judged from Fig. I which shows that epicenter distribution of large seismic events of the past agrees fairly well with epicentral field and density of earthquake epicenters of the last decades of the twentieth century. Epicenters of older ancient earthquakes correspond generally within uncertainties of coordinate determination to the zones of higher density of epicenters. The main features of their distributions are as follows: 1 . Sublatitudinal zone of epicenters in the north of the Khubsugul region; 2. Sublatitudinal zone of epicenters stretching south of $50^{\circ}$ parallel; 3 . Zone of north-western trend in the south-west of Mongolia. In addition, epicenters of some ancient earthquakes are beyond the isolines $n=4$ of epicenter density map.

As a whole, the map of epicenters agrees rather well with the epicentral field of earthquakes analyzed in the work [28]. A marked increase in the number of earthquakes did not change the character of epicenter distribution which as before rather distinctly represents nonuniformity of seismic process development in Mongolia. Analysis of the epicentral field shows that the main seismic activity is developed in central and western areas, however, the boundary separating territories with high and low seismicity by "critical" $105^{\circ} \mathrm{E}$ meridian [28], should be transferred to the east to $108^{\circ} \mathrm{E}$. East of this longitude the epicentral field is characterized by slight scattered seismicity without rather dense earthquake groups. Bands of higher concentration of earthquake epicenters, most often in agreement with fault zones, are distinguished on the map. In some places sites of higher concentration of epicenters have the shape of compact "spots" which can both correspond to the zones of fault intersection and localize with no spatial relation to the known destructive crustal elements. The areas of high concentration of epicenters correspond most often to focal zones of large seismic events of the second half of 
the last century. Rather prominent is the relation between large earthquakes and high density of epicenters in Busingol basin of the Khubsugul region within which over the period of instrumental observations two earthquakes with $\mathrm{Kp}=14$ and one with $\mathrm{Kp}=16$ were recorded which were accompanied by lengthy aftershock series. The same situation is typical of the regions of $1967 \operatorname{Mogod}(M=7.8 ; K p=17), 1970$ Uregnur $(\mathrm{M}=7 ; \mathrm{Kp}=16)$ and 1974 Takhiinshar $(\mathrm{M}=6.9 ; \mathrm{Kp}-16)$ [28] earthquakes and their aftershock sequences.

The map of epicenters of 38002 earthquakes with $\mathrm{Kp}>=7$ served as a basis for construction of a map of epicenter density (Fig.I). Density of epicenters is determined by calculation of a number of shocks occurred in elementary $0.2^{\circ} \times 0.3^{\circ}$ $(\sim 22 \times 22 \mathrm{~km})$ areas. These sizes of areas overlap the values of uncertainties of epicenter coordinate determination of the majority of earthquakes. A number of shocks occurred in the elementary area was attributed to the center of the corresponding area. Isolines of epicenter density were constructed by Kriking method and have following gradation $-n=4 ; n=10 ; n=25 ; n=50 ; n=100 ; n=500 ; n=1000$; $\mathrm{n}=1500$ and $\mathrm{ft}=2000$ seismic events. Isolines of earthquake epicenter density make possible distinguishing the local zones with high concentration of seismic events $n>100$. Such local zones are well-defined in the regions of 1967 Mogod, 1970 Uregnur and Busingol earthquakes of $1991(\mathrm{MLH}=6.5 ; \mathrm{Kp}=16.2)$. Shock density in the zone of the Busingol earthquake was over 2000 events. It can be noted that similarity in formation of epicentral field is observed in these regions. First, hypocenters of large earthquakes of these regions are located in the plane of sublongitudinal strike. Second, these regions are generally bounded by "waste" zones, shown in the Fig. 1 by lines of "hatch" type. Third, these regions are characterized by high density of shocks due to lengthy aftershock series [35-37]. It is worth noting that the region of Tunka basin is also bounded by "waste" zones and characterized by high density of shocks, and a chain of "hatch" sites obviously tracing some boundary are observed along the latitude $50^{\circ} \mathrm{N}$.

On the other hand, the map of epicenter density enables determination of boundaries of large seismically active areas. Northern and southern areas with boundary between them in the latitude around $48^{\circ} \mathrm{N}$ is distinguished in Fig.l. The northern area, besides the above division in the $50^{\circ} \mathrm{N}$ latitude, can be separated into western and central parts by $96^{\circ} \mathrm{E}$ meridian. In the southern area the demarcation line between western and central parts corresponds to $95^{\circ} \mathrm{E}$. Such delimitation of epicentral field is in a good agreement with a scheme of seismically active regions of Mongolia used in the study [28], and forms the basis of regionalization of the territory in investigating seismic regime at the detailed area level.

\section{Spatio-temporal variations of seismic regime}

Variations of seismic regime in various spatio-temporal groups of earthquakes is traditionally characterized by variations of parameters of the recurrence plot. This plot shows distribution of the number of seismic events on a scale of dynamic 
evaluation of an earthquake and in loglinear system of coordinates has, as a rule, a linear form $[38,39]$. Nonlinear form of the recurrence plots observed at times, may result from nonlinearity (at logarithmic scale) of a scale of dynamic evaluation of an earthquake over a full range of measurements and also insufficient representativeness of spatio-temporal data sampling. Slope $\gamma$ of the recurrence plot characterizes relationship between the numbers of small and large earthquakes and depends largely on the scale of energy assessment of shocks used, the type of tectonic rock flow, degree of crushing and inhomogeneity of strata and energy range of earthquakes considered $[40,41]$. The other parameter of the recurrence plot is its level characterizing the seismic activity $A$ when the energy class $\mathrm{K}$ is fixed, i.e., the number of shocks of this class generally normalized in space and time. Formula of the recurrence plot for the scale of energy classes can be represented as [42]:

$$
\lg N=\lg A-\gamma(K-K p),
$$

where $\mathrm{N}$ is the number of seismic events, $\mathrm{Kp}$ is energy class fixed, most often $\mathrm{Kp}=10$ and $\gamma$ is positive. It is to be noted that when $\gamma$ parameter determined as a slope of the recurrence plot of earthquakes is positive, physical content of this coefficient, which characterizes decrease of the number of large shocks in the studied sampling of seismic events, is lost. Negative $\gamma$ representing physical significance of this parameter as a slope of the recurrence plot, is used in the study. With this notion, increase of a slope of the recurrence plot of earthquakes indicates that in earthquake sampling there is a displacement of the number of events toward larger shocks and maximum $\gamma$ points generally to availability of a shock of high energy class in sampling.

The plots of earthquake recurrence given below are calculated for various spatio-temporal samplings of initial data optimal in size. Notion of optimality is associated with a large number of shocks for a short time interval when the number of earthquakes is distributed over the whole range of energy class that, unfortunately, could not take place universally. In this connection parameters of the plots of earthquake recurrence of Mongolia have been determined using annual, two-year and three-year samplings of shocks of all representative energy classes $9<\mathrm{Kp}<17$ (complete sampling) and shocks with $9<\mathrm{Kp}<14$ (incomplete sampling) with a step of one year. Parameters of the plots of earthquake recurrence for four areas and five regions were calculated for three-year volume of data with a step of one year with corresponding ranges of representative energy classes of shocks (Table).

For the reasons given above and explained below we used $g$ parameter with negative sign which corresponds to regression equation $\lg \mathrm{N}=\lg \mathrm{A}+\gamma(\mathrm{K}-\mathrm{Ko})$. Slopes $\gamma$ of the recurrence plots have been determined using two methods. The least-square method was used in the first case. Formulas of the method of maximum likelihood, recommended in [43] to determine slope $\gamma$ of the recurrence plot when 
the number of earthquakes is $\mathrm{N}<1000$, were applied in the second version of calculation. Average number of earthquakes with $\mathrm{Kp}>9$ in two-year shock samplings of Mongolia approaches 500 events. The number of shocks in three-year data samplings for four areas and five regions most often was less than 1000 .

Fig. 2 and 3 shows variations (with time) of $\gamma$ slope of the recurrence plots of Mongolian earthquakes, estimated for annual, two-year and three-year data samplings with $\mathrm{Kp}>9$ by the least-square method and the method of maximum likelihood. Comparison of Figures 2 and 3 shows that $y$ values calculated by the least-square method correspond as a whole to those determined by the method of maximum likelihood, $\gamma$ variations in the first case generally exceed fluctuations of $\gamma$ parameter obtained by the method of maximum likelihood. The plots built using the method of maximum likelihood of complete and incomplete data samplings practically coincide. In some cases, the plots obtained by the least-square methods of complete and incomplete data samplings differ greatly. The most significant differences take place in 1967, 1970, 1974, 1987 and 1989-1991.

Fig.4 presents variations (with time) of $\gamma$ slope of the plots of earthquake recurrence of northern Mongolia. Here, as in Fig. 2 and 3, significant differences in the plots obtained by the least-square method with complete and incomplete data samplings are observed in 1966-1968 and 1988-1990. The similar pattern is observed in the central area. In southern area /coefficients differ in 1973-1975, 1986-1988 and 1997-1998. In western Mongolia noticeable /differences are in 1969-1971, 19731975 and 1986-1992. In the Khankhuhei-Bolnai region the greatest difference in plots obtained by the least-square method with complete and incomplete data samplings takes place in 1990-1992. In the Orkhon-Tola region two periods of significant difference of the parameter, in 1966-1968 and 1988-1990, are observed and in the Khubsugul region in 1990. In the Mongolia-Gobi region these differences are in 1997-1998 and in the Mongolia-Altai in 1969-1971, 1973-1975 and 19861988.

Sum seismic energy is calculated for three-year samplings of seismic events. The maximums of sum seismic energy released at earthquakes in Mongolia, are observed in 1966-1971, 1973-1975, 1986-1992 and 1997-1998. The greater part of sum seismic energy was released in the process of shocks occurred in northern and central areas of Mongolia (Table). Correlation coefficient of the plots of sum seismic energy of earthquakes in Mongolia and these regions is $p=0.99$. Correlation coefficient of the plots of sum seismic energy of earthquakes in Mongolia and western and southern areas does not exceed $p<0.2$. However, the plots of sum seismic energy of earthquakes of western and southern areas are in fairly good agreement and correlation coefficient of the plots is $p=0.65$. Spatio-temporal distribution of sum seismic energy of earthquakes has a more complex form in regions than in areas. The greater part of sum seismic energy was released in the process of shocks which occurred in the Orkhon-Tola region and correlation coefficient of the plots of sum seismic energy of earthquakes of Mongolia and this 
region is $p=0.98$. A high level of correlation of the plots of sum seismic energy of earthquakes of the Khubsugul and Khankhuei-Bolnai regions $(p=0.99)$ can be noted. The other plots have correlation coefficients $p<|0.2|$ which do not increase at relative displacement of the plots in time.

Variations of the seismic process in space and time reflect the steps of the recent geodynamic activization of the territory of Mongolia and individual regions. These steps are traced rather well in essential differences of $\gamma$ slopes of the plots of earthquake recurrence obtained by the least-square method with complete and incomplete data samplings. The greatest differences are in 1967-1974, 1987 and 1990-1991. At the same time increase of the level of sum seismic energy radiated by earthquakes of various regions took place. Processes of sum seismic energy release by earthquakes of central and northern areas practically coincide in time. Similar pattern is observed for shocks of southern and western areas. Since there is no correlation between the plots of sum seismic energy release by earthquakes of these couples of areas, it is suggested that the main seismic process was formed singly in the north and in the southwest of Mongolia. To solve this problem there is a need to investigate and analyze spatio-temporal variations of dynamic parameters of earthquake sources of Mongolia.

Variations of basic parameters of seismic regime of various regions of Mongolia give grounds to conclude that seismic process was nonstationary and epicentral field was inhomogeneous. Noiistationarity and inhomogeneity of seismicity result mainly from large earthquakes and their aftershock sequences. Since the condition of quasistationarity of the seismic process and averaging of the seismic regime is inferred in seismic zoning of territories, in zoning of nonstationary and inhomogeneous seismic fields the spatio-temporal fluctuations of seismicity caused by aftershock and swarm sequences of shocks should be taken into account. In spatial aspect the problems of seismic zoning are solved by correspondence of large earthquakes to zones of influence of tectonically active faults and paleoseismodislocations. As for temporal sphere, investigations of variations of seismicity and mean rate occurrence of earthquakes need be carried out. Integrally, the problem should be formulated as investigation of spatio-temporal variations of state of stress and strain of the medium and seismicity in tectonically active areas and regions of Mongolia. 
Figure captions

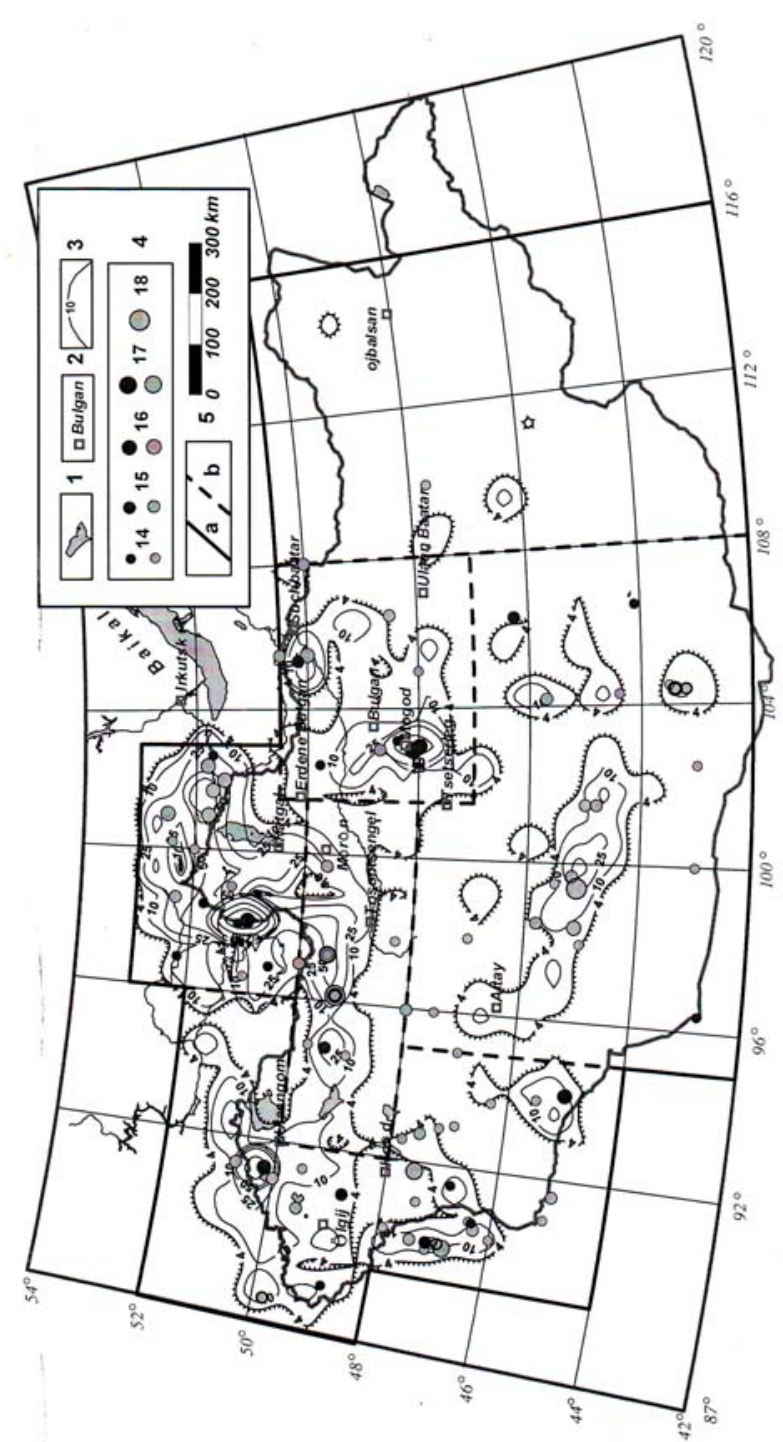

Fig. 1. The map of earthquake epicenter density of Mongolia

1 - basic faults, 2 - lakes, 3 - towns, aimak centers and large somons; 4 isolines of earthquake epicenter density; 5 - epicenters of instrumentally determined (1964-1999, black) and ancient (1761-1963, gray) large earthquakes with energy classes Ke" 14; 6 - boundaries of the studied territories of: a - Mongolia, b - regions. 


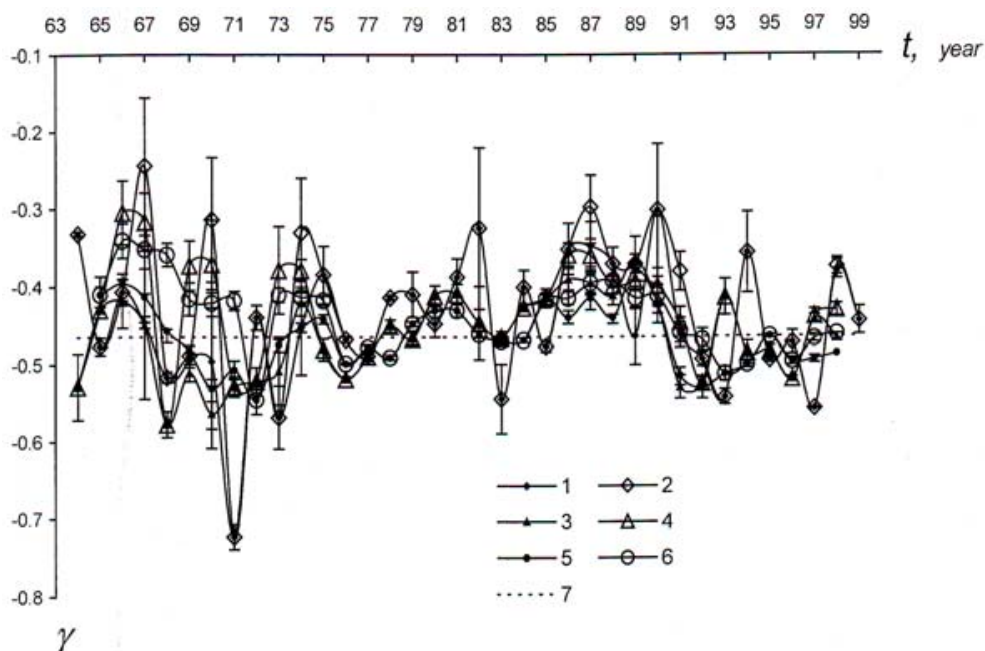

Fig.2. Variations of slope $\gamma$ of the recurrence plots of earthquakes of Mongolia

$1-2,3-4,5-6$ - parameter $\gamma$ is determined by the least-square method for incomplete and complete annual, two-year and three-year earthquake samplings, 7 - parameter $\mathrm{g}$ is computed for all shocks.

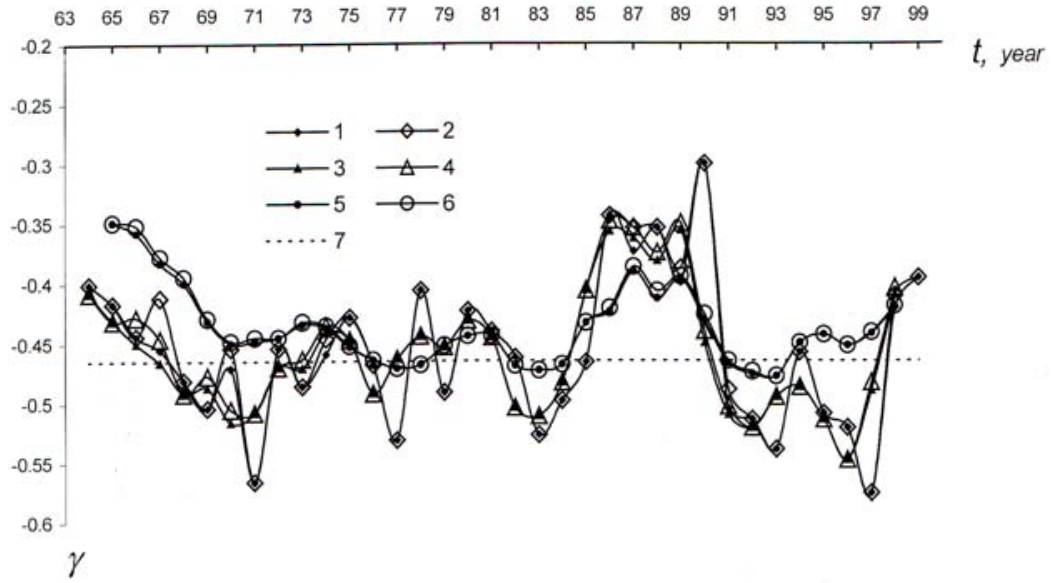

Fig.3. Variations of the slope $\gamma$ of the recurrence plots of earthquakes of Mongolia

$1-2,3-4,5-6$ - parameter $g$ is determined by the method of maximum likelihood for incomplete and complete annual, two-year and three-year earthquake samplings, 7 - parameter $\gamma$ is computed for all shocks. 
$\begin{array}{lllllllllllllllllll}63 & 65 & 67 & 69 & 71 & 73 & 75 & 77 & 79 & 81 & 83 & 85 & 87 & 89 & 91 & 93 & 95 & 97 & 99\end{array}$

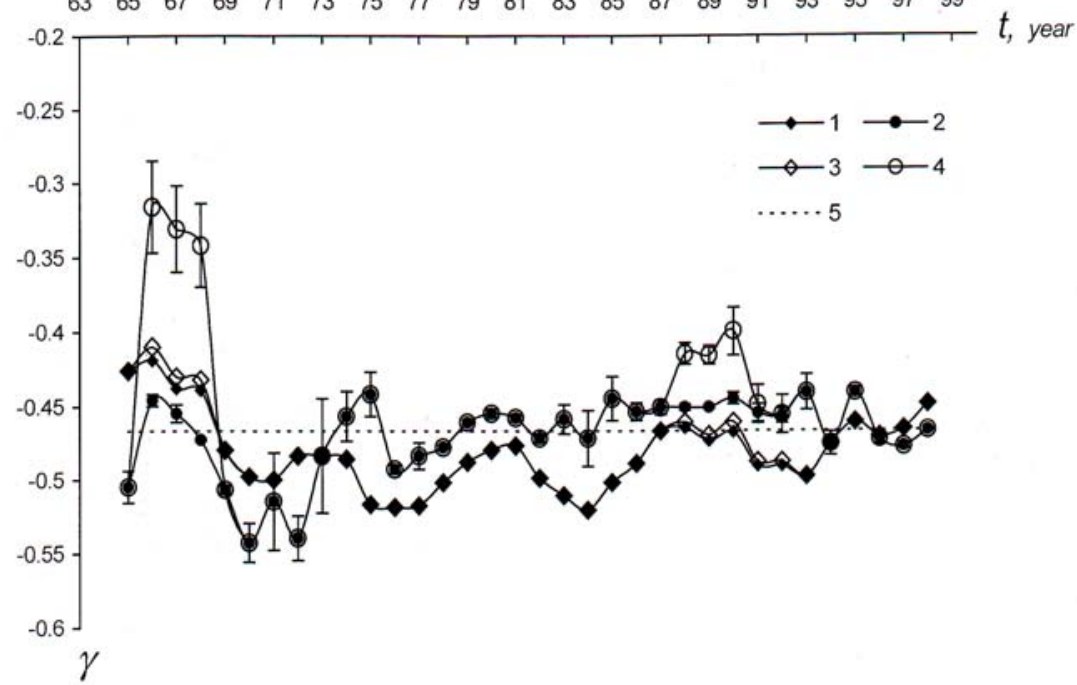

Fig.4. Variations of slopes $\gamma$ of the recurrence plots of earthquakes in northern area

1 and 3 - parameter $g$ is determined by the method of maximum likelihood for incomplete and complete three-year earthquake samplings; 2 and 4 - parameter $g$ is determined by the least-square method for incomplete and complete three-year earthquake samplings; 5 - parameter $g$ is computed for the all shocks of northern area. 


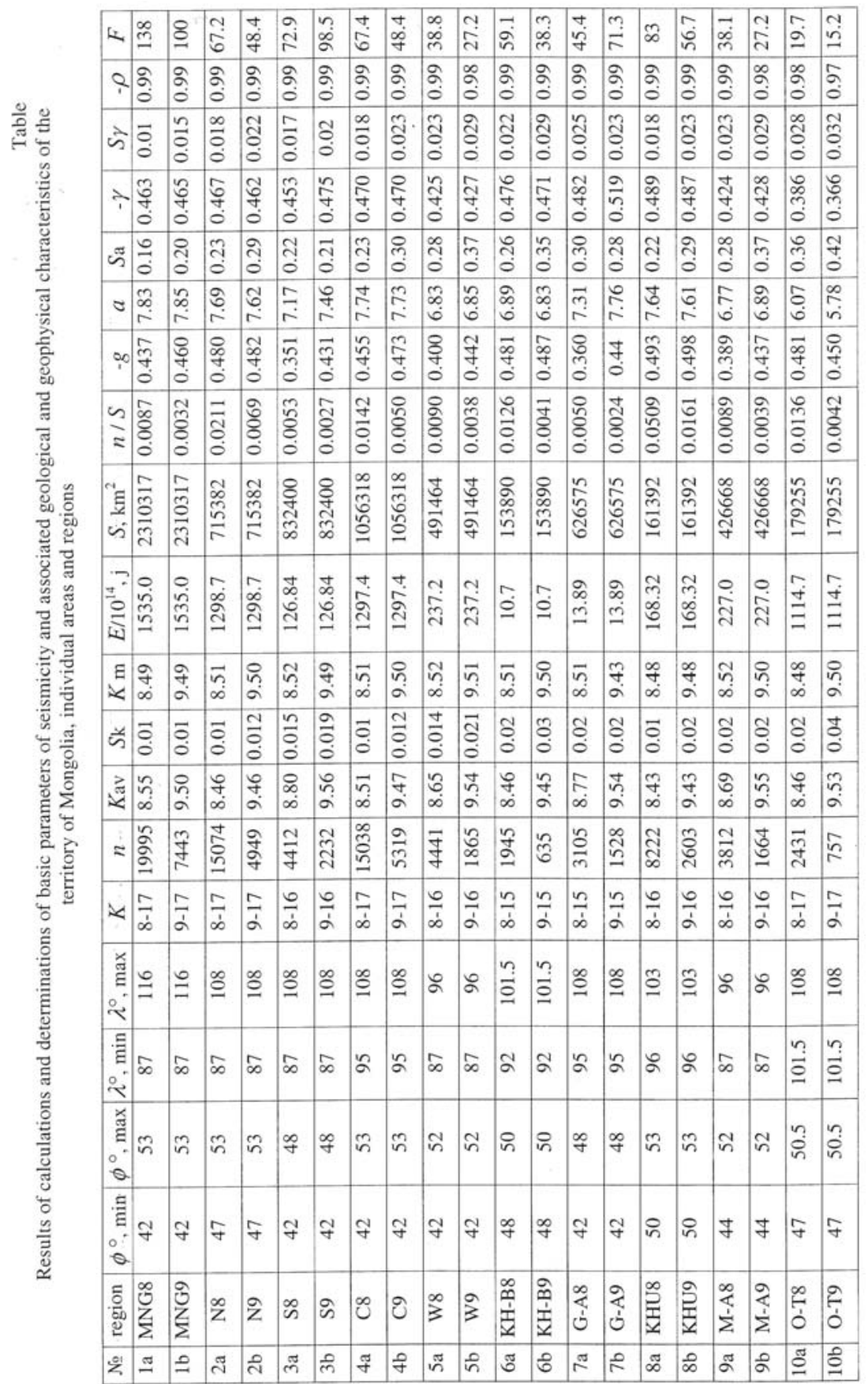




\section{References}

1. Baljinnyam I, Bayasgalan A., Borisov B.A. et al. Rupturs of major earthquakes and active deformation in Mongolia and its surroundings// Geological society of America. Memoir 181. $1993.59 p$.

2. Molnar P., Tapponnier P. Cenozoic tectonics of Asia: Effects of continental collision // Science. 1975. V.189. No. 4201. P.419-426.

3. Misharina L.A., Melnikova V.I., Baljinnyam I. South-western boundary of the Baikal rift zone from the data on earthquake focal mechanism // Vulkanoligia i seismologia. 1983. $\mathrm{N}^{\circ} 2$. P.74-83.

4. Kochetkov V.M., Khilko S.D., Zorin Yu.A. et al. Seismotectonics and seismicity of the Khubsugul region. Novosibirsk: Nauka, 1993. 182 p.

5. Molnar P., Kurushin R.A., Kochetkov V.M. et al. Deformation and faulting at large earthquakes in Mongolia-Siberian region // Deep structure and geodynamics of Mongolia-Siberian region / Logatchev N.A.(ed-). Novosibirsk: Nauka, 1995. P.5-55.

6. Klyuchevskii A.V., Selenge L. Comparative analysis of dynamic parameters of earthquake sources in Mongolia // Deep structure and geodynamics of Mongolia-Siberian region// Logatchev N.A. (ed). Novosibirsk: Nauka. 1995. P.55-64.

7. Solonenko A., Solonenko N., Melnikova V. and Shteiman E. The seismicity and earthquake focal mechanisms of the Baikal rift zone //Bull. Centres Rech. Explor.- Prod. Elf. Aquit. 1997. V.25. No.I. P. 207-231.

8. Logatchev N.A., Zorin Yu.A. Evidence and cause of the two-stage development of the Baikal rift// Tectonophysics. 1987. V.143. P. 225-234.

9. Logatchev N.A., Zorin Yu.A. Baikal rift zone: structure and geodynamics // Tectonophysics. 1992. V.208. P.273-286.

10. Logatchev N.A. History and geodynamics of the lake Baikal rift in context of the Eastern Siberia rift system: a review // Bull. Centres Rech. Explor.-Prod. Elf. Aquit. 1993. V.17. No.2. P.353-370.

11. Gao S., Davis P.M., Liu H. Et al. Seismic anisotropy and mantle flow beneath the Baikal rift zone //Nature. 1994. V. 371. P.149-151.

12. Logatchev N.A. Basic structural features and geodynamics of the Baikal rift zone // Physical mesomechanics. 1999. T.2. JSfol/2. P.163-170.

13- Logatchev N.A. On reasonable zoning of geologic structure of the Lake Baikal basin // Doklady AN. 2002. T.375. JN5. P.657-661.

14. Tapponnier P., Molnar P. Active faulting and Cenozoic tectonics of the TienShan, Mongolia and Baikal regions // J. Geophys. Res. 1979. V.84. P.34253459.

15. Radon J. C, Leevers P.S. Analysis of fracture growth using two parameters: recent achievements // Physical mesomechanics. 1999. T.2. Jvfel/2. P.97104. 
16. Milanovskii E.E. Rifting and pulsation of the Earth // Rifts of the lithosphere: evolution, tectonics, magmatic, metamorphic and sedimentary complexes, mineral resources. Materials of the international conference (8-th lecturing devoted to A.N. Zavaritskii). Ekaterinburg: 2002. P.6-15.

17. Djadjkov P.G., Melnikova V.I., Sanjkov V.A. et al. Recent dynamics of the Baikal rift: episode of compression and subsequent extension in 1992-1996 // Doklady AN. 2000. T.372. JVal. P.99-103.

18. Klyuchevskii A.V. Spatio-temporal variations of seismic moments of earthquake sources in the Baikal region // Doklady AN. 2000. T.373. JSTs5. P.681-683.

19. Klyuchevskii A.V. Localization of initial actions of mantle diapir in the zone of the Baikal rift // Doklady AN. 2001. T.381. Ns2. P.251-254.

20. Klyuchevskii A.V. On the nature of spatio-temporal variations of seismic moments of earthquakes in the Baikal region // Doklady AN. 2002. T.384. N25. P.687-691.

21. Panin V.E., Elsukova T.F., Angelova G.V. Wave character of distribution of fatigue cracks on the surface of polycrystalline aluminum in cyclic submergence //Physical mesomechanics. 2002. T.5. Xe3. P.93-99.

22. Klyushnitchenko A.B., Panin S.V., Startsev O.V. Investigation of deformation and destruction at meso- and macroscale levels of reinforced plastics at statistical and cyclic extension // Physical mesomechanics. 2002. T.5. We3. P. 101-116.

23. Keilis-Borok V.I., Knopoff L., Rotwain I., Allen C.R. Intermediate term prediction of occurrence times of strong earthquakes // Nature. 1988. V. 335. No. 6192. P.690-694.

24. Sykes L.R., Jaume S.C. Sesimic activity on neighboring faults as a longterm precursor to large earthquakes in the San Francisco Bay area // Nature. 1990. V.348. No. 6302. P.595-599.

25. Habermann R.E., Wyss M. Background seismicity rates and precursory seismic quiescence: Imperial Valley, California // Bull. Seism. Soc. Amer. 1984. V.74. No. 6. P. 1743-1755.

26. Wiemer S., Wyss M. Seismic quiescence before the Landers $(M=7.5)$ and Big Bear (M=6.5) 1992 earthquakes // Bull. Seism. Soc. Amer. 1994. V.84. No.3. P.900-916.

27. Sobolev G.A. Stages of origination of the large Kamchatka earthquakes // Vulkanologia i seismologia. 1999. JV«4/5. P.63-72.

28. Khilko S.D., Kurushin R.A., Kochetkov V.M. et al. Earthquakes and the basics of seismic zoning in Mongolia. M.: Nauka, 1985. 222 p.

29. Golenetskii S.I. Seismic monitoring in East Siberia at the boundary of XXI century. Geophysical research in East Siberia at the boundary of XXI century. Novosibirsk: Nauka, 1996. P.102-105.

30. Equipment and methods of seismometric observations in the USSR// M.: 
Nauka, 1974. $242 \mathrm{p}$.

31. Instruction about the order of production and processing of observations at seismic stations of Unitary system of seismic observations of the USSR // M.: Nauka, 1982. 271 p.

32. Rautian T.G. On determination of earthquake energy at distances up to 3000 km // Experimental seismics // Tr. In-ta Fiziki Zemli AN SSSR, 1964. JVs32 (193). P.86-93.

33. Golenetskii S.I. Evaluation of efficiency of seismic station network and the map of representativeness of the Baikal zone earthquakes // Implementation of a computer in seismological practice. M.: Nauka, 1985. P.80-85.

34. Golenetskii S.I., Demjanovich V.M., Filina A.G. Representativeness of earthquakes of South Siberia and Mongolia in 1960-1990 // Seismicity and seismic zoning of Northern Eurasia. Vyp.I. M.: OIFZ RAN, 1993. P.83-85.

35. Tsibulchik I.D., Filina A.G. Earthquakes of Altai and Sayan // Earthquakes in the USSR in 1973. M.: Nauka, 1976. P.101-107.

36. Filina A. G. Earthquakes of Altai and Sayan// Earthquakes in the USSR in 1991. M.: OIFZ RAN, 1997. P.38-39.

37. Golenetskii S.I. Earthquakes in the Baikal and Transbaikal regions // Earthquakes in the USSR in 1991. M.: OIFZ RAN, 1997. P.39-47.

38. Richter C.F. Elementary Seismology // W.H. Freeman. San Francisco, 1958. $768 \mathrm{p}$.

39. Bune V.I., Gzovskii M.V., Zapolskii K.K. et al. Methods of detailed investigation of seismicity // Tr. IFZ AN SSSR. M.: Izd-vo AN SSSR, 1960. $\mathrm{N}^{\circ} 9$ (176). $327 \mathrm{p}$.

40. Kronrod T.L. Parameters of seismicity for the main highly seismic regions of the World //Computer seismology. M.: Nauka, 1984. Vyp.17. P.36-58.

41. Sadovskii M.A., Bolkhovitinov L.G., Pisarenko V.F. Deformation of geophysical medium and seismic process. M.: Nauka, 1987. 101 p.

42. Riznitchenko Yu.V. Problems of seismology. M.: Nauka, 1985. 405 p.

43. Zhalkovskii N.D., Muchnaya V.I. On accuracy of determination of a slope of the recurrence plot for earthquakes // Geologia i geofizika. 1987. JNTsIO. P. $121-129$ 